\title{
Artículos de Estudiantes
}

\section{Más allá del sujeto. Habitando la transición \\ Beyond the subject. Inhabiting the transition}

\author{
FELIPE NIÑO'
}

\begin{abstract}
Resumen: El artículo bosqueja algunas consecuencias y tareas que se abren a partir de una crítica de la metafísica de la sustancia realizada a partir de Nietzsche. Se intenta poner en tensión la figura moderna del hombre y las formas de subjetivación contemporáneas. El artículo es una invitación a abandonar la espera, añoranza y postergación de otro ser humano por venir. Sirviéndose de una propuesta ética que pone en el centro al cuerpo y a la vida, se plantea la pregunta acerca de cuáles pueden ser las nuevas formas de habitar nuestro tiempo y de vivenciar las fuerzas en disputa que nos constituyen sin dejar esa tarea para el futuro. Finalmente, se propone que esas nuevas formas de ser en el mundo no pueden aspirar a ser definitivas si pretenden ampliar la vida y tampoco se producirán a partir de cultivos a gran escala.
\end{abstract}

Palabras Clave: metafísica; sustancia; subjetivación; humanidad.

Abstract: The article outlines some consequences and tasks that open up from a critique of the metaphysics of substance made from Nietzsche onwards. An attempt is made to put in tension the modern figure of man and the contemporary forms of subjectivation. The article is an invitation to abandon the waiting, longing and postponement of another human being to come. Using an ethical proposal that places the body and life at the center, it raises the question of what can be the new ways of inhabiting our time and experiencing the forces in dispute that constitute us without leaving this task for the future. Finally, it is proposed that these new ways of being in the world cannot aspire to be definitive if they seek to expand life, nor will they be produced from large-scale cultivation.

Key Words: metaphysics; substance; subjectification; humanity.

Cómo citar: Niño, F. (2021). Más allá del sujeto. Habitando la transición. Cuadernos Filosóficos, 18. https://doi.org/10.35305/cf2.vil8.157

Publicado bajo licencia Creative Commons Atribución-SinDerivadas 4.0 Internacional [CC BY-ND 4.0] 


\section{Introducción}

Queremos exponer algunas de las consecuencias que se desprenden una vez que hemos negado la existencia de un fundamento que subyace y se expresa en el ser humano. Recordamos que el llamado a un sustrato para delimitar y definir a la humanidad nunca se da como un proceso espontaneo y neutral. Los atributos que le son asignados al sujeto de la modernidad expresan características que poseen aquellos que ocupan lugares de poder o son depositarios del mismo y lo ejercen en diferentes procesos de dominación, explotación y exterminio de la vida en todas sus manifestaciones. Dicho lo anterior, nos detendremos en algunas perspectivas que ofrecen autores contemporáneos sobre los procesos de subjetivación en los que estamos inmersos con el objetivo de indagar si hay algún margen de acción para intervenir e incidir afirmativamente en lo que somos. El punto de partida para la acción se apoya en una de las grandes tareas que legó Nietzsche a la posteridad. Esta consiste en ubicar al cuerpo, es decir, a la vida, en el centro como valor supremo. Es el cuerpo y no la razón lo realmente poderoso. Es nuestro cuerpo, el de cada uno, el que debe ser explorado, vivenciado y a partir del cual podremos habitar de otra manera nuestro tiempo construyendo existencias que afirmen y respetan la vida.

Pensar el más allá de lo humano puede tornarse pura especulación o promesa, pero puede también dinamizar nuestro presente. Podemos hacer una crítica radical del humanismo pero no por eso dejamos de portar su enfermedad. Si eventualmente el tipo hombre es superado seguramente no estemos vivos para presenciarlo, no al menos de forma definitiva $y$ generalizada. Una vez abandonado el postulado de que el ser humano está en constante progreso, no hay certeza de que los devenires futuros de nuestra especie sean mejores. Incluso, tenemos que convivir con la posibilidad de que este ser humano se arraigue y la dominación y explotación de las demás formas de vida se exacerbe. Que podamos servir de puente hacia otras formas de ser en el mundo es algo que puede no suceder. La cría del "hombre nuevo" o la llegada del suprahombre pueden nunca llegar. Así como el proletariado encontró consuelo en la promesa de que un día sería abolida la propiedad privada y eliminada la sociedad de clases, tal vez así, les suceda a los que anhelan otra forma de lo humano si lo postergan para el futuro. Los trabajadores que siguen esperando no han cesado de alimentar con su carne al Leviatán. Qué hacer entonces para que la crítica al humanismo y al antropocentrismo se materialice en formas concretas de habitar nuestro tiempo? El llamado es a dejar de esperar. Nosotros, demasiado humanos para abandonar definitivamente esto que 
somos, tal vez podamos al menos imprimir un estilo en nuestra existencia, alcanzar una impronta. No habrá un momento de ruptura sino de pequeñas fisuras y nuevas pinceladas. Para esto, debemos volvernos artesanos de nosotros mismos. Avocarnos a esta materia plástica hasta desdibujar nuestra humanidad. Partimos de una crítica al humanismo "encadenado con un "Sujeto" patriarcal, colonial y especista; con un "Yo" racional, unitario y totalizante; con un "Individuo" concebido, o bien como un monismo egocéntrico de una metafísica de la sustancia, - bien como una bipolaridad hilemórfica - aunque ambos casos impliquen un principio de individuación que privilegia al individuo como una relación estable de materia-forma" (Cangi, 2021 , p. 121). A través de este artículo solo buscamos reunir algunas propuestas para habitar la transición. No se trata de una nueva forma de subjetividad que se espera alcanzar, por el contrario, partimos de la idea de que solo pueden gestarse aglutinaciones y disgregaciones de las fuerzas en lucha que conforman al ser humano. Únicamente unidades momentáneas que se disgregan, que sirven como puentes hacia nuevas combinaciones de la multiplicidad de fuerzas que son obturadas bajo la ficción del sujeto. La propuesta ética es asumida aquí como respuesta concreta e inmediata para intentar abandonar lo que hoy somos. Es la forma en la que nos vemos obligados a afrontar nuestro presente a falta de salidas políticas inmediatas. Pero también, partiendo de que no es deseable un cultivo a gran escala de nuevos seres humanos. Una ética radical como forma de construir lo político, y en ese sentido, como tránsito hacia nuevas formas de lo humano. Sumado a esto, nos interesa pensar el tipo de comunidad que podría propiciar nuevos devenires sin anular las singularidades. Aquí solo se pretende proponer la necesidad de instaurar nuevas experiencias que sirvan de laboratorio para habitar lo que hay en nosotros pero también para abrirnos a nuevas posibilidades. Experiencias frágiles, inestables, fugaces, abiertas, móviles. Abandonar la esperanza y habitar el tránsito de manera afirmativa.

\section{El sujeto como ficción lógica}

Para realizar la crítica al sujeto de la modernidad tomamos como punto de partida la crítica que Nietzsche realiza a la metafísica. El análisis procura derribar la idea de que existe un fundamento, una sustancia o esencia que subyace y se manifiesta en cada fenómeno. Intenta llevar a cabo una "deconstrucción de los conceptos que organizan en un sistema piramidal centrado en torno a un principio que opera como arkhé-dios, fundamento del ser, del pensar y del obrar" (Cragnolini, 2016, p.38). Una vez "muerto Dios", su lugar es ocupado por el sujeto. La metafísica no se abandona, Dios sigue presente tras el velo de la secularización. El hombre asume su lugar y debe ser el que brinde fundamento a los ámbitos ontológico, gnoseológico y 


\section{FELIPE NIÑO}

Más allá del sujeto. Habitando la transición

Artículos de Estudiantes

ético-político. Este sujeto aparece como "una unidad sustancial espiritual, un portador único y unitario - un sustrato- de todo nuestro pensamiento y de nuestra acción, una sustancia espiritual que se desliga del devenir y permanece igual a sí misma garantizando la identidad de la persona humana" (Niemeyer, 2012, p.494). El hombre reemplaza a Dios y se convierte en creador. Como tal, necesita que en sí mismo haya regularidad y cohesión para que lo creado permanezca siempre igual, pero también para que sus acciones puedan ser bien direccionadas. Según ciertas filosofías que se impusieron en occidente, el ser humano debe momificar la realidad para 'sanar' sus irregularidades, desviaciones, conflictos y cambios. El sujeto como ficción lógica busca subsanar el fondo agonístico y trágico de lo humano para dar lugar a un orden calculado, con regularidad y previsión. El objetivo es iluminar toda zona que permanezca fuera del dominio del ser humano. El sujeto representa al mundo en su conciencia, lo hace 'existir' como imagen pero siempre referido a sí mismo. Ahora bien, este teatro en el que el hombre pretende esclarecer el mundo va acompañado de la razón como su aliada. Esta última le permitiría al hombre extraer la verdad de cada cosa, sus regularidades y su funcionamiento para ponerlo todo a su servicio. "Si no hay nada opaco para la razón, eso significa que nada se le resiste. Si nada se le resiste, puede dominar todo. [...] De lo que se trata es del espíritu tiránico del filósofo, y de su intento de dominar, de "tornar pensable todo lo que existe", y asegurárselo en el modo del fundamento" (Cragnolini, 2016, p. 40). Sumado a lo anterior, el hombre también sería depositario de otros atributos. Es autónomo, es decir, tiene la capacidad de proveerse su propia ley a través de la razón. Pero además, esta posibilidad de darse una legislación se da en función de su libertad. Esta última se manifiesta en la propiedad de uno mismo en el ejercicio de la libertad y la apropiación de la realidad que se materializa en la vida social y en la relación con los demás seres vivientes. Relación que está marcada por la búsqueda de sujetar y dominar a lo otro, a lo diferente. Como vemos, el sujeto se asienta sobre un supuesto fundamento que lo haría portador de ciertas características propias que son legitimadas al afirmar la existencia de una esencia. Estos atributos del ser humano reflejarían su naturaleza y lo llevarían a ser de una forma determinada.

\section{Definición de lo humano}

La búsqueda de una definición delimitada de lo humano nunca es ingenua. La actitud crítica que proponemos ante el humanismo radica en su intento por ofrecer un concepto de hombre que le permite construir identidades calculables, predecibles, dóciles y productivas que se puedan insertar en un determinado orden social que se erige sobre prácticas de dominación, explotación y exterminio de aquello que queda por fuera del concepto de lo humano. Esta 


\section{FELIPE NIÑO}

Más allá del sujeto. Habitando la transición

Artículos de Estudiantes

separación puede ser caracterizada a través de lo que Agamben denomina como maquina antropológica. A través de ésta se pone

en juego la producción de lo humano mediante la oposición hombre/animal, humano/inhumano, [...] mediante una exclusión (que es también y siempre ya una captura) y una inclusión (que es también y siempre ya una exclusión). [...] La máquina produce en realidad una especie de estado de excepción, una zona de indeterminación en la que el afuera no es más que la exclusión de una adentro y el adentro, a su vez, tan solo la inclusión de una afuera. (Agamben, 2006, p. 75)

La creación de una matriz de inteligibilidad de lo humano se torna necesaria para lograr la subyugación y control de las poblaciones y de los demás seres vivos. Pero también es necesario crear una serie de jerarquizaciones al interior de lo humano y por fuera de él. El dominio por la mera fuerza física nunca es suficiente para lograr que el orden se mantenga sin fisuras. Un poder coercitivo genera subordinación a través del miedo y la violencia física pero esta forma de ejercer el poder ha demostrado a lo largo de la historia su fragilidad. Aquí podemos retomar el ejemplo que nos ofrece Foucault en relación al tránsito de un poder soberano que hace morir o deja vivir hacia un poder disciplinario que administra la vida, es decir, que hace vivir o deja morir. En relación con esto último, podemos pensar en la suerte que tienen que afrontar los cuerpos con discapacidades $\circ$ las identidades transgénero. Este poder se manifiesta por su ausencia. Estas formas de vida quedan por fuera de la matriz de inteligibilidad de lo humano y por ese motivo no alcanzan la existencia necesaria para ser tenidos en cuenta en la gestión de lo común. Al ser menos que humanos y quedar por fuera de su marco se los abandona hasta morir.

\section{Producción en serie de la subjetividad. Sujeto contemporáneo}

Este sujeto al que nos referimos es un sujeto sano, patriarcal, colonial, especista, productivo, propietario de sí y de todas las formas de vida. Como propusimos al principio de este escrito, nuestra intención es poder habitar el tránsito hacia nuevas formas de lo humano. Sin embargo, nos debemos enfrentar al hecho de que la subjetividad es fabricada, modelada, vendida y consumida de forma serializada en cada rincón del planeta. Según Mark Fisher, el capitalismo está tan arraigado que parece más fácil esperar el fin del mundo que el de este modo de producción. El capitalismo en la actualidad estaría tan asentado que ocuparía todo el horizonte de lo pensable. No haríamos más que oscilar a través de un "mesianismo débil" con pequeñas esperanzas o sin ninguna. Toda alternativa real se encontraría clausurada. También 


\section{FELIPE NIÑO}

Más allá del sujeto. Habitando la transición

Artículos de Estudiantes

propone que ya no se puede hablar de una confrontación entre la subversión y la captura a nivel cultural. A diferencia de esto, habría una "precorporación, a través del modelado preventivo de los deseos, las aspiraciones y las esperanzas por parte de la cultura capitalista" (Fisher, 2016, p. 31). Lo 'alternativo' e 'independiente' serían estilos dominantes del mainstream. Por su parte, el filósofo surcoreano Byung-Chul Han nos propone que ya no habitamos sociedades disciplinarias sino sociedades de rendimiento. El análisis foucaultiano no daría cuenta de los cambios psíquicos y topológicos de las sociedades que habitamos, o al menos, de las sociedades industrializadas que describe Han. Nos enfrentamos a un nuevo tipo de sujeto del que ya no se espera obediencia. Los nuevos sujetos son emprendedores de sí mismos. Habría una mayor desregulación en las sociedades actuales. Lo que caracterizaría a las nuevas sociedades es la ausencia de obstáculos. Este poder ilimitado derivaría en un exceso de positividad. En esta sociedad "los proyectos, las iniciativas y la motivación reemplazan la prohibición, el mandato y la ley. [...] La sociedad de rendimiento [...] produce depresivos y fracasados" (Han, 2018, p. 26). Si el paso de un poder soberano a un poder disciplinario está marcado por una búsqueda de mayor productividad, este último también es abandonado cuando la técnica disciplinaria alcanza su límite por la prohibición. Para superar la productividad se da un tránsito hacia un esquema positivo del poder que resulta mucho más eficiente. Sin embargo, como marcábamos más arriba, este exceso de responsabilidad recae en el sujeto y lo lleva a generar rendimientos de forma permanente y a optimizar su vida hasta el colapso. Una de las particularidades de este sujeto es que ya no requiere de un poder externo que lo incite a la productividad. En este caso el verdugo ha sido incorporado dando como resultado la autoexplotación. Que no exista un poder coactivo externo no deriva en libertad. Esta última aparece como la obligación de maximizar el rendimiento. Esta libertad deriva en violencia. En una sociedad en la que todo es posible el fracaso debe ser asumido completamente por el sujeto. El resultado es el autoreproche y a la agresión de sí mismo.

Sin embargo, la forma en que los individuos viven su subjetividad no está dada únicamente por un proceso externo en el que son alienados, oprimidos o sometidos bajo la subjetividad asignada. No queremos negar que factores sociales, económicos, geográficos, culturales, entre otros, condicionen a las personas. Tampoco buscamos convertir un problema estructural y de dominio público en uno privado derivando en una exacerbación del sujeto autónomo y responsable de sí mismo como propone Han. Pero afirmamos que a pesar de esto hay un margen de acción para intervenir en la propia subjetividad. También hay "una relación de expresión y de creación, en la cual el individuo se reapropia de los componentes de la subjetividad produciendo un proceso [...] de singularización" (Guattari \& Rolnik, 2013, p. 48). 


\section{FELIPE NIÑO}

Más allá del sujeto. Habitando la transición

Artículos de Estudiantes

Con esto último nos referimos a la negación de un sujeto como una unidad cerrada y acabada que contiene una naturaleza que lo define. Primero porque esa naturaleza no es más que el producto de marcos legales, epistemológicos y ético-políticos que modelan los cuerpos y sujetan las 'almas'. Pero también, porque no hay un sustrato que buscar en el interior de lo humano. Hay una multiplicidad de fuerzas en disputa, un campo de batalla, una materia plástica que puede adoptar diferentes formas.

\section{Más allá del sujeto}

Nuestra intención es habitar el tránsito hacia un más allá de lo humano. No pretendemos afirmar que dentro de las posibles alternativas que puede haber para habitar nuestro tiempo la que ofrecemos sea correcta ni la más segura de ser materializada. Para empezar, no queremos negar el fondo agonístico de la vida. En ese sentido, evitamos caer en una nueva concepción unívoca de lo humano que dé lugar a un sistema totalizador que lejos de abrirse a nuevas posibilidades busque igualar. Si una alternativa política fuera hoy posible de igual forma no comulgamos con el cultivo del "hombre nuevo" a gran escala. Esto implicaría postergar el tránsito hacia otras posibilidades de lo humano para cuando llegue finalmente el momento idóneo y no habría una apertura real a la multiplicidad y el cambio. No esperamos llegar un día al puerto final, tampoco alcanzar un estado de bienestar que derivaría de la forma realizada y definitiva de lo humano. Ahora bien, no negamos que nos gusta fantasear con un nuevo ordenamiento político que pudiera propiciar las condiciones para el despliegue de nuevas potencias, pero dado nuestro interés y pocas miras, solo tenemos la pretensión de instar a no esperar a que las condiciones ideales lleguen. Por esto proponemos darle una mayor centralidad a la construcción de una ética. Esto tal vez sea una muestra de la falta de imaginación política de nuestro tiempo. O peor aún, que esta dificultad para construir un proyecto colectivo no sea más que el reflejo de nuestra derrota. De ser así, no deja de ser menos importante hacer que nuestras vidas se tornen más vitales y alegres aunque todo parezca estar girando en falso.

\section{Emergencia del cuerpo}

Si Nietzsche emprende una guerra contra la voluntad de verdad es porque esta búsqueda ha desvalorizado la vida. A través de conceptos se ha pretendido petrificar lo que deviene. Ese deseo de alcanzar fundamentos absolutos a través de la primacía de la razón ha degradado la vida. Nietzsche pretende darle un lugar central al cuerpo, el lugar que le corresponde como 


\section{FELIPE NIÑO}

Más allá del sujeto. Habitando la transición

Artículos de Estudiantes

campo donde se entrecruzan las fuerzas y del que se desprenden todas las herramientas $y$ artificios que se usan para vivir. El autor ofrece la "posibilidad de afirmar la potencia crítica y creativa de los cuerpos para el desarrollo de una ética de la duda constante y de la transvaloración de los valores" (Cano, 20I5, p. 108). Pero también, anclando "su propuesta perspectivista en las coordenadas de la vida y de la muerte, así como en el horizonte de la incertidumbre, la provisoriedad y el "peligroso quizás"” (p. 108). El autor busca reivindicar todo lo asociado a lo sensible. Lo que deviene, se transforma y muere, es decir, lo que tiene un vínculo estrecho con la vida. El cuerpo, en esta nueva jerarquía que privilegia la vida, es una "pluralidad viviente, contingente y fluida, ha de proporcionar un punto de apoyo temporal y contingente (no ahistórico, ni absoluto, o desencarnado) en el que asentar nuestras perspectivas, valores y narraciones" (Cano, 20I5, PP. IIO-III). En ese sentido, el cuerpo aparece como nuevo centro epistémico que tiene como objetivo no la obtención de verdades o certezas. Al contrario de un pensamiento muerto, el cuerpo como "gran razón" busca todo aquello que aumente su vitalidad y le haga descubrir nuevas potencias. Un pensamiento que necesita del cambio para abrirse a la multiplicidad. En este modelo, el cuerpo ya no aparece opuesto a la razón sino que esta última no es más que una de las manifestaciones del primero. La razón como instrumento del cuerpo ya no pretende resultados absolutos. Si tiene un correlato con la vida debe aceptar que los nuevos conceptos, relatos, valoraciones y saberes serán frágiles, momentáneos y perecederos. Esta disposición a aceptar la fragilidad de toda construcción humana pone en el centro del debate qué concepción de lo humano puede derivar de esa fragilidad. Como propusimos más arriba, una apertura real a la experimentación ilimitada de nuevas formas de lo humano no puede asentarse en un suelo firme. Las nuevas formas de vivenciar lo que habita en nuestros cuerpos implicara maneras transitivas, maleables y siempre puestas en tensión. Aceptamos que habrán momentos en que es necesario replegar las fuerzas para sobrevivir, pero para conservarse debe haber expansión, es decir, cambio.

Siguiendo con el filósofo alemán, encontramos en su filosofía una invitación a vivenciar las fuerzas que habitan nuestro cuerpo de manera afirmativa. Aunque estemos habitados por fuerzas caóticas, instintos, pasiones, sentimientos e intensidades que nos desbordan esto no significa que debamos sepultar o coaccionar eso que nos habita. El trabajo que debemos desarrollar es el de un artista. Si hemos olvidado nuestro cuerpo intentado acondicionarnos a un universal de lo humano de ahora en más evitaremos vivenciar nuestras potencias a partir de un guía, marco normativo, modelo, filosofía o filósofo que imitar. Nos vemos en la obligación de vivenciar nuestra singularidad asumiendo la tarea de escultores de nosotros mismos. Parece difícil alcanzar la autenticidad de un artista pero no podemos olvidar que cada cuerpo es 
irrepetible. Por este motivo, una vida que sea el correlato de las determinaciones del cuerpo también lo será. Nietzsche nos invita a no aceptar el modelo de "otro que este ahí acabado y le sea ofrecido como si este tuviera que anticiparle las líneas y los colores de su cuadro" (Nietzsche, 2007, p.197), ya que no haremos más que renegar de nosotros mismos. Si solo nos dedicamos a copiar los gestos, las prácticas y estilos de los demás seremos toda la vida partidarios. Pero nos recuerda que esta tarea de adquirir un propio estilo es costosa. Será mucho "el aburrimiento que ha de vencerse, mucho el sudor necesario, hasta haber encontrado uno sus colores, su pincel, su lienzo! Y entonces no es todavía uno, ni con mucho, maestro de su arte de vivir, pero si al menos dueño del propio taller" (p. 197). Sin embargo, quisiéramos aclarar que este "cuidado de si" se distancia del "diseño de si" entendido desde la perspectiva moderna del empresario de sí mismo. A diferencia de esto, el "cuidado de si" persigue la práctica reflexiva de la libertad, donde la libertad se constituye en la condición ontológica de la ética" (Cangi, 202I, p. 157). Esta libertad tal vez consista en aceptar aquello que en nuestro cuerpo tiene carácter de necesidad, es decir, conocer lo que podemos y lo que no. No se trata tanto de la imagen que se ofrece al mundo exterior ni de poner la vida al servicio de la productividad y el ahorro, sino de "«la inocencia del devenir» como un arte del derroche vital y afirmativo" (Cangi, 202I, p. 158).

\section{7. ¿Qué comunidad?}

Aunque al hacer hincapié en una ética del cuerpo como forma de propiciar nuevos devenires de lo humano se corra el riesgo de aislarnos, consideramos que también puede ser una forma de reconciliarnos con nuestra soledad. No una soledad absoluta, sino una que intercalaremos con la conformación de nuevos tipos de comunidad. Podemos encontrar aliados insospechados, pero no los encontraremos en una masa abstracta que puede contener a nuestros enemigos. No todos son nuestro prójimo, hay algunos que incluso desean nuestra destrucción. No lo pueden ser en nuestro caso neonazis y explotadores, por nombrar solo dos ejemplos de una lista que se extiende. No por esto dejamos de anhelar otro tipo de sociedad en la que pudieran desplegarse múltiples formas de existencia y, que además, nos posibilitara coexistir pacíficamente con todos los seres vivos. Pero ya que la utopía está lejos, insistimos en la necesidad de establecer alianzas basadas en afinidades electivas. Un pathos de la distancia. Peter Pál Pelbart se pregunta "¿Cómo sostener un colectivo que preserve la dimensión de la singularidad? ¿Cómo crear espacios heterogéneos, con tonalidades propias, atmósferas distintas, en los que cada uno se enganche a su modo? ¿Cómo mantener una disponibilidad que propicie los encuentros, pero que no los imponga, una atención que permita 


\section{FELIPE NIÑO}

Más allá del sujeto. Habitando la transición

Artículos de Estudiantes

el contacto y preserve la alteridad? ¿Cómo dar lugar al azar, sin programarlo? ¿Cómo sostener una "gentileza" que permita la emergencia de un hablar allí donde crece el desierto afectivo?" (Pelbart, 2009, p. 44). Su respuesta es la conformación de una comunidad hecha de suavidad que se entrecruza con el dolor. Una comunidad que se resiste a los intercambios productivos y a un socialitarismo despótico.

\section{Referencias}

Agamben, G. (2016). Lo abierto: el hombre y el animal. Adriana Hidalgo.

Cangi, A. (202I). Pensar la caída del humanismo en tiempos de antropodicea. En S. M. Cabanchik \& S. Botticelli (Eds.), Humanismo y posthumanismo: Crisis, restituciones y disputas (pp. 131-162). Teseo.

Cano, G. (2012). Diccionario Nietzsche. Conceptos, obras, influencias y lugares.

Cano, V. (20I5). Nietzsche. Galerna.

Cragnolini, M (2016). Moradas nietzscheanas. Del sí mismo, del otro y del "entre". La Cebra.

Fisher, M. (2016). Realismo capitalista. ¿No hay alternativa? Caja Negra.

Guattari, F., \& Rolnik, S. (20I3). Micropolítica. Cartografías del deseo. Tinta Limón.

Han, B. (2018). La sociedad del cansancio. Herder.

Nietzsche, F. (2007). Humano, demasiado humano (Vol. 2). Akal.

Pál Pelbart, P. (2016). Filosofía de la deserción. Nihilismo, locura y comunidad. Tinta Limón. 